\title{
Liver condition of Holstein cows affects mitochondrial function and fertilization ability of oocytes
}

\author{
Hiroshi TANAKA ${ }^{1) *}$, Shun TAKEO ${ }^{1) *}$, Takahito ABE1), Airi KIN¹), Koumei SHIRASUNA ${ }^{1)}$, \\ Takehito KUWAYAMA ${ }^{1)}$ and Hisataka IWATA ${ }^{1)}$ \\ 1) Tokyo University of Agriculture, Kanagawa 243-0034, Japan
}

\begin{abstract}
The aim of the present study was to examine the fertilization ability and mitochondrial function of oocytes derived from cows with or without liver damage. Oocytes were collected from the ovaries of cows with damaged livers (DL) and those of cows with healthy livers (HL), subjected to in vitro maturation, and fertilized in vitro. A significantly high abnormal fertilization rate was observed for oocytes from DL cows compared to oocytes from HL cows. The time to dissolve the zona pellucida by protease before fertilization was similar between the two liver conditions, whereas after fertilization treatment this time was shorter for DL cows than for HL cows. The percentage of oocytes with equivalent cortical granule distributions underneath the membrane was greater for in vitro matured oocytes from HL cows, whereas an immature distribution pattern was observed for oocytes from DL cows. In addition, a greater percentage of oocytes derived from HL cows released cortical granules following fertilization compared with oocytes from DL cows. Mitochondrial function determined by ATP content and membrane potential were similar at the germinal vesicle stage, but post-in vitro maturation, the oocytes derived from HL cows showed higher values than DL cows. The mitochondrial DNA copy number in oocytes was similar between the two liver conditions for both the germinal vesicle and post-in vitro maturation oocytes. In conclusion, liver damage induces low fertilization, likely because of incomplete cortical granule distribution and release, and the maturation of oocytes from DL cows contain low-functioning mitochondria compared to their HL counterparts.
\end{abstract}

Key words: Cow, Fertilization, Liver condition, Mitochondria, Oocytes

(J. Reprod. Dev. 62: 235-240, 2016)

$\mathbf{M}$ ilk production from dairy cows has increased over the past several decades because of genetic and management improvements [1]. However, the fertility of dairy cows has decreased [2, 3]. The reason for this decline is unclear, but it is thought that the rapid increase in milk synthesis following parturition exceeds the energy intake from food, causing body condition loss and metabolic disorder and resulting in liver dysfunction including fatty liver $[1,4,5]$.

Although the relationship between the negative energy condition and infertility has been reported previously [2,6], few studies have examined the relationship between liver damage and the low quality of bovine oocytes [7-10]. In these studies, one of the prominent features of oocytes derived from cows with liver damage was the high frequency of abnormal fertilization [8]; however, the molecular mechanism underlying fertilization abnormalities are unclear. Normal fertilization occurs through well-orchestrated events including sperm penetration, calcium oscillation, cortical granule (CG) exocytosis, and zona hardening. These processes are regulated by versatile enzymes and interactions between small organelles, including the endoplasmic

Received: October 23, 2015

Accepted: January 9, 2016

Published online in J-STAGE: January 30, 2016

(C)2016 by the Society for Reproduction and Development

Correspondence: H Iwata (e-mail: h1iwata@nodai.ac.jp)

* Tanaka $\mathrm{H}$ and Takeo $\mathrm{S}$ contributed equally to this work.

This is an open-access article distributed under the terms of the Creative

Commons Attribution Non-Commercial No Derivatives (by-nc-nd) License

$<\mathrm{http}$ ://creativecommons.org/licenses/by-nc-nd/4.0/>. reticulum and mitochondria [11]. While accumulating evidence has shown that mitochondrial function is crucial for successful nuclear maturation, fertilization, and subsequent development [12-16], there have been no reports regarding mitochondrial functions in oocytes derived from cows with liver damage. In the present study, we examined the effect of the liver condition on the fertilization outcome, CG distribution, and zona hardening following fertilization as well as the mitochondrial quality and quantity of oocytes.

\section{Materials and Methods}

\section{Chemicals and media}

All chemicals were purchased from Nacalai Tesque (Kyoto, Japan) unless otherwise stated. The media used for in vitro maturation (IVM), in vitro fertilization (IVF), and in vitro culture (IVC) were based on synthetic oviductal fluid (SOF) supplemented with $5 \mathrm{mM}$ taurine and $1 \mathrm{mM}$ glutamine [17]. The in vitro maturation medium was composed of SOF containing $10 \%$ fetal calf serum (FCS) $(5703 \mathrm{H}$, ICN, Costa Mesa, CA, USA), $5.56 \mathrm{mM}$ glucose, and essential and non-essential amino acids (M5550 and M7145, Sigma-Aldrich, St. Louis, MO, USA). The in vitro fertilization medium was composed of SOF containing $5 \mathrm{mg} / \mathrm{ml}$ fatty acid-free bovine serum albumin and $10 \mathrm{IU} / \mathrm{ml}$ heparin (Sigma-Aldrich). The in vitro culture medium was composed of SOF containing essential and non-essential amino acids, $1.5 \mathrm{mM}$ glucose, and 1\% FCS. 


\section{Diagnosis of liver conditions and donor cow selection}

The diagnosis of liver conditions and donor cow selection were conducted as described in our previous report [7, 8]. Briefly, the liver conditions were visually diagnosed based on the surface and sectional appearance by onsite veterinarians at the slaughterhouse. Cows were divided into three categories based on their liver conditions: cows with healthy liver (HL cows), cows with partially damaged liver, and cows with completely damaged liver (DL cows). Only HL or DL cows were used, while cows with partially damaged livers were not used. The diagnosis of damaged liver conditions during the experiments included hepatorrhagia in $30.6 \%$ of samples, liver telangiectasia in $18.5 \%$, liver abscess in $14.1 \%$, perihepatitis in $10.1 \%$, cholangiohepatitis in $8.3 \%$, fatty liver in $6.8 \%$, puerperal liver in $5.8 \%$, and others in $5.8 \%$.

Holstein cows ranging in age from 30 to 100 months were selected. Cows older than $>100$ months were not used because of the effect of aging on oocytes [18-20]. To minimize the effects of the donor's estrous cycle, ovaries with normal morphology and a functional corpus luteum and 1 or 2 dominant non-cystic follicles were selected and transferred to phosphate-buffered saline (PBS) at $30^{\circ} \mathrm{C}$ and taken to the laboratory within $3 \mathrm{~h}$.

\section{Oocyte collection, IVM, IVF, and IVC}

Cumulus-oocyte complexes (COCs) were aspirated from the antral follicles (3-6 $\mathrm{mm}$ in diameter) using an 18-gauge needle connected to a $10-\mathrm{mL}$ syringe. The COCs were cultured in a $100-\mu 1$ droplet of IVM medium (10 COCs/drop). After $21 \mathrm{~h}$ of IVM, COCs were fertilized with frozen-thawed semen from a Japanese black bull as described previously [8]. The fertilization ability of the semen has been demonstrated in our previous reports $[8,20,21]$. After $5 \mathrm{~h}$ of co-incubation with the sperm, COCs were washed three times and cultured in $100 \mu 1$ of IVC medium (10 zygotes/drop). The culture conditions of IVM, IVF, and IVC were $38.5^{\circ} \mathrm{C}$ in an atmosphere of $5 \% \mathrm{CO}_{2}$ in air with maximum humidity.

\section{Assessment of fertilization rate}

Eighteen hours after insemination, oocytes were denuded of cumulus cells by vortexing ( $6 \mathrm{~min}$ ) and fixed. The ooplasmic lipid was removed in acetic acid/ethanol (1:3) and mounted on a slide glass. The pronuclei were counted using an inverted microscope (Olympus, Tokyo, Japan) following orcein staining. Fertilization was classified into three groups: normal fertilization (Norm), oocyte with two pronuclei; polyspermic fertilization (Poly), oocyte with more than three pronuclei; and unfertilized (Non), oocyte without a pronucleus.

\section{Assessment of zona pellucida dissolution}

Zona pellucida (ZP) dissolution was assayed based on a previous study by Coy et al. [22] with some modifications. The ZP was collected from denuded oocytes using a narrow pulled pasture pipette, washed three times in PBS, and transferred to a $10 \mu$ l droplet of PBS containing $0.1 \%$ pronase (a ZP/drop) (Roche Diagnostics, Risch-Rotkreuz, Switzerland). The ZP was continuously observed under an inverted microscope (Olympus) powered by warm plate at $38.5^{\circ} \mathrm{C}$ until the zona was no longer visible under the microscope. The time required for ZP dissolution was measured.

\section{Detection of CG distribution}

CG distribution was examined as previously described [22, 23]. Denuded oocytes were fixed with PBS- $0.1 \%$ polyvinylalcohol (PVA) containing $4.0 \%(\mathrm{w} / \mathrm{v})$ paraformaldehyde for $30 \mathrm{~min}$ at room temperature. These oocytes were treated with PBS containing 3\% $(\mathrm{w} / \mathrm{v})$ bovine serum albumin and then treated with PBS-0.1\% PVA containing $0.1 \%(\mathrm{v} / \mathrm{v})$ Triton X-100 for $5 \mathrm{~min}$. Oocytes were then incubated in PBS- $0.1 \%$ PVA containing $100 \mathrm{mg} / \mathrm{ml}$ fluorescein isothiocyanate-labeled peanut agglutinin for $30 \mathrm{~min}$ for staining. Next, oocytes were mounted on slides using Vectashield (Vector Laboratories, Burlingame, CA, USA). Fluorescent images were acquired using a fluorescence microscope (BZ-8000, Keyence, Osaka, Japan). CG distribution was classified into three groups: complete, CGs migrated to the cortex and formed a continuous monolayer underneath the oolemma; incomplete, CGs distributed as small aggregates and single particles underneath the oolemma; and immature, CGs diffused throughout the ooplasm (Fig. 1). After IVF treatment, CG distribution was classified into two groups: oocytes released CG content with scant fluorescent in oocytes or oocytes incompletely released CGs with strong fluorescence remaining in the oocytes.

\section{Measurement of ATP content}

ATP was measured as reported previously [18] and according to the manufacturer's protocol (ATP assay kit, Toyo-Ink, Tokyo, Japan).

\section{Assessment of mitochondrial membrane potential}

The mitochondrial membrane potential of oocytes was measured using a mitochondria specific-fluorescence probe, MitoTracker Orange CMTM Ros (M-7510; Molecular Probes, Eugene, OR, USA), according to a previous study with some modifications [24, 25]. Briefly, COCs were denuded and incubated for $30 \mathrm{~min}$ in PBS containing $0.3 \%$ (w/v) PVA and $200 \mathrm{nM}$ MitoTracker Orange CMTM Ros. After staining, the oocytes were mounted on a glass slide. Fluorescence images were captured using a fluorescence microscope. The fluorescence intensity of the whole oocyte was pixel-transformed using Image-J software (NIH, Bethesda, MD, USA).

\section{DNA extraction and measurement of mitochondrial DNA copy number}

Mitochondrial DNA (mtDNA) copy number in the oocytes was measured as reported previously [18, 20]. Briefly, 10 oocytes were lysed in $6 \mu \mathrm{l}$ lysis buffer $(20 \mathrm{mM}$ Tris, $0.4 \mathrm{mg} / \mathrm{ml}$ pronase $\mathrm{K}, 0.9 \%$ Nonidet- 40 , and $0.9 \%$ Tween 20 ) at $55^{\circ} \mathrm{C}$ for $30 \mathrm{~min}$, followed by $98^{\circ} \mathrm{C}$ for $5 \mathrm{~min}$. The mtDNA number was then determined by real-time polymerase chain reaction (PCR) using a Rotor-Gene 6500 real-time rotary analyzer (Corbett Research, Sydney, NSW, Australia). The PCR mixture $(20 \mu \mathrm{l})$ was composed of $6 \mu \mathrm{l}$ DNA extract, $0.5 \mu \mathrm{M}$ of each primer set (Bovine mitochondrial ND5; NC006853; $1.82 \mathrm{~kb}$ region from base 12,109 to base 13,929 ; 5'-ATTTACAGCAATATGCGCCC-3' and 5'-AAAAGGCGTGGGTACAGATG-3'), and SsoFast EvaGreen Supermix (Bio-Rad, Hercules, CA, USA). PCR was performed with initial denaturation at $95^{\circ} \mathrm{C}$ for $5 \mathrm{~min}$, followed by 40 cycles at $95^{\circ} \mathrm{C}, 58^{\circ} \mathrm{C}$, and $72^{\circ} \mathrm{C}$ for $30 \mathrm{sec}$ at each temperature. A standard curve was generated for each run using 10 -fold serial dilutions. The external standard was the PCR product of the corresponding gene cloned into a vector using the Zero Blunt TOPO PCR cloning kit 

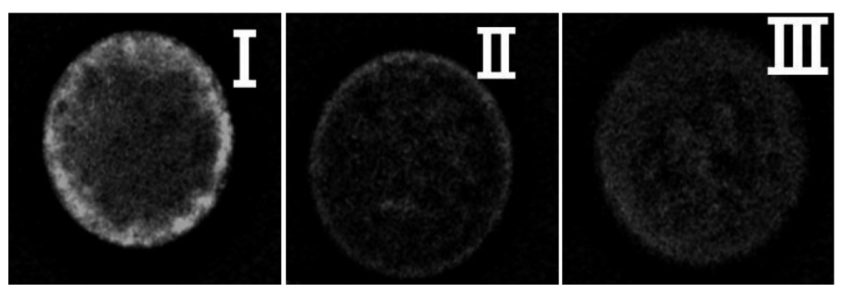

Fig. 1. Representative images of CGs in in vitro-matured oocytes (I-III). I; Complete distribution of CGs. II; Incomplete distribution of CGs. III; Immature distribution of CGs.

(Invitrogen, Carlsbad, CA, USA); the sequence of the product was confirmed before use. In all trials, the amplification efficiency was more than 1.9 .

\section{Experimental design}

Experiment 1: In experiment 1, the effect of liver conditions on fertilization rate was examined. Twenty COCs were randomly selected from pooled COCs derived from HL and DL cows and subjected to IVM and IVF treatment, after which the fertilization rate was determined. The experiment was repeated 6 times using different oocyte series in a total of $24 \mathrm{DL}$ and $24 \mathrm{HL}$ cows (4 cows/replicate).

Experiment 2: The effect of liver conditions on ZP dissolution by protease before and $12 \mathrm{~h}$ after IVF treatment was examined. Twenty COCs were randomly selected from pooled COCs derived from HL and DL cows and the ZP was subjected to the ZP dissolution test before and after IVF treatment. The experiment was repeated three times with different oocyte series for a total of $9 \mathrm{HL}$ and $9 \mathrm{DL}$ cows (3 cows/replicate).

Experiment 3: We examined effect of liver conditions on the CG distribution in oocytes after both maturation and fertilization. Approximately 20 COCs were randomly selected from pooled COCs derived from HL and DL cows and subjected to IVM. At the end of IVM and $12 \mathrm{~h}$ after IVF treatment, approximately 20 and 10 oocytes were randomly selected and the CG distribution was assessed, respectively. The experiment was repeated four times with different oocytes series for a total of $20 \mathrm{HL}$ and $20 \mathrm{DL}$ cows ( 5 cows/replicate).

Experiment 4: The effect of liver condition on the mtDNA copy number in oocytes was examined. mtDNA copy number was compared within cohort oocytes collected from individual cows because of the great variation in mtDNA among donor cows [18]. Twenty COCs were randomly collected from individual cows and divided into two groups. Ten oocytes were used to evaluate mtDNA copy number before or after IVM. A total of $20 \mathrm{HL}$ and $20 \mathrm{DL}$ cows were used.

Experiment 5: In experiment 5, we examined the effect of the liver conditions on the mitochondrial membrane potential of immature and matured oocytes. We measured the membrane potential of 10 oocytes before and after IVM. The experiment was repeated 4 times using differential ovary series. A total of $20 \mathrm{HL}$ and $20 \mathrm{DL}$ cows were used (5 cows/replicate).

Experiment 6: In this experiment, we examined the effect of the liver conditions on ATP content in immature and mature oocytes. ATP content in the oocytes was compared within the cohort oocytes collected from individual cows because of the great variation in ATP among donor cows, and the ATP value obtained from five cohort oocytes closely reflected the average ATP content of oocytes for each donor cow [18]. COCs were collected from individual cows and the ATP content of oocytes in germinal vesicle (GV) and post-IVM oocytes was examined. A total of $30 \mathrm{HL}$ and $50 \mathrm{DL}$ cows were used.

\section{Statistical analysis}

All data were compared between HL and DL cows using Student's $t$-test. The data for the fertilization rate of oocytes included arcsine transformed before analysis. Values less than 0.05 were considered significantly different.

\section{Results}

\section{Experiment 1}

The fertilization rates of oocytes derived from HL or DL cows are presented in Table 1. The rate of polyspermic fertilization was greater for oocytes collected from the ovaries of DL cows than those from $\mathrm{HL}$ cows (HL vs. DL, $21.7 \pm 2.7 \%$ vs. $40.8 \pm 1.7 \%, \mathrm{P}<0.05$; Table 1), while the rate of normal fertilization was lower for DL cows than for HL cows (HL vs. DL, $66.7 \pm 1.8 \%$ vs. $49.2 \pm 1.7 \%$, $\mathrm{P}<0.05$; Table 1).

\section{Experiment 2}

When the ZP collected from mature oocytes was incubated in medium containing pronase, the time required to dissolve the $\mathrm{ZP}$ was similar between the two liver conditions. In contrast, after IVF treatment, the ZP-dissolving time was longer for oocytes derived from HL cows than those from DL cows (HL vs. DL, 133.0 vs. 114.0 sec, $\mathrm{P}<0.05$; Table 2).

\section{Experiment 3}

CG exocytosis is vital for zona hardening following fertilization, and the present study categorized the CG distribution of mature oocytes into 3 categories (Fig. 1). The percentage of oocytes with CGs densely assembled underneath the oolemma (Category 1) was significantly higher for oocytes collected from HL cows than for those collected from DL cows. Additionally, oocytes from HL cows showed a significantly lower rate of incomplete CG distribution compared to oocytes from DL cows (Table 3). After IVF treatment, the rate of oocytes completely releasing CGs was significantly greater for oocytes derived from HL cows than for those derived from DL cows (HL vs. DL, 65.7 vs. 33.3\%, $\mathrm{P}<0.05$; Table 3).

\section{Experiment 4}

Next, we compared the mtDNA copy number and functions in oocytes between the two liver conditions. Mitochondrial number determined based on mtDNA copy number was similar between the two liver conditions in both the GV and after maturation cultures (Table 4).

\section{Experiment 5}

The mitochondrial membrane potential determined using membrane potential-dependent fluorescent dyes was similar for GV stage oocytes between the two liver conditions, whereas the fluorescence intensity was greater for mature oocytes from HL cows than from 
Table 1. Effect of liver conditions on fertilization rate

\begin{tabular}{cccccc}
\hline \multirow{2}{*}{$\begin{array}{c}\text { Liver } \\
\text { conditions }\end{array}$} & \multirow{2}{*}{$\begin{array}{c}\text { No. of } \\
\text { trials }\end{array}$} & \multirow{2}{*}{$\begin{array}{c}\text { No. of } \\
\text { oocytes }\end{array}$} & \multicolumn{3}{c}{ Rate of fertilization ${ }^{\mathrm{A}}(\mathrm{Mean} \pm \mathrm{SE})$} \\
\cline { 4 - 6 } & & & Norm & Poly & Non \\
\hline HL & 6 & 120 & $66.7 \pm 1.8^{\text {a }}$ & $21.7 \pm 2.7^{\text {a }}$ & $11.6 \pm 2.3$ \\
DL & 6 & 120 & $49.2 \pm 1.7^{\mathrm{b}}$ & $40.8 \pm 1.7^{\mathrm{b}}$ & $10.0 \pm 2.0$ \\
\hline
\end{tabular}

A Fertilization was categorized as normal fertilization (Norm), polyspermic fertilization (Poly), and non-fertilization (Non). a-b: Values with different letters differ significantly $(\mathrm{a}-\mathrm{b} ; \mathrm{P}<0.05)$.

Table 2. Effect of liver conditions on zona pellcida solubility

\begin{tabular}{ccccc}
\hline \multirow{2}{*}{$\begin{array}{c}\text { Liver } \\
\text { conditions }\end{array}$} & $\begin{array}{c}\text { No. of } \\
\text { trials }\end{array}$ & No.of ZP & \multicolumn{2}{c}{$\begin{array}{c}\text { Time required to dissolve } \\
\text { (seconds, Mean } \pm \text { SE) }\end{array}$} \\
\cline { 3 - 5 } & & & Before IVF & After IVF \\
\hline HL & 3 & 60 & $104.8 \pm 3.1$ & $133.0 \pm 2.5^{\text {a }}$ \\
DL & 3 & 60 & $101.6 \pm 2.2$ & $114.0 \pm 3.9^{\mathrm{b}}$ \\
\hline
\end{tabular}

Values with different letters differ significantly $(\mathrm{a}-\mathrm{b} ; \mathrm{P}<0.05)$.
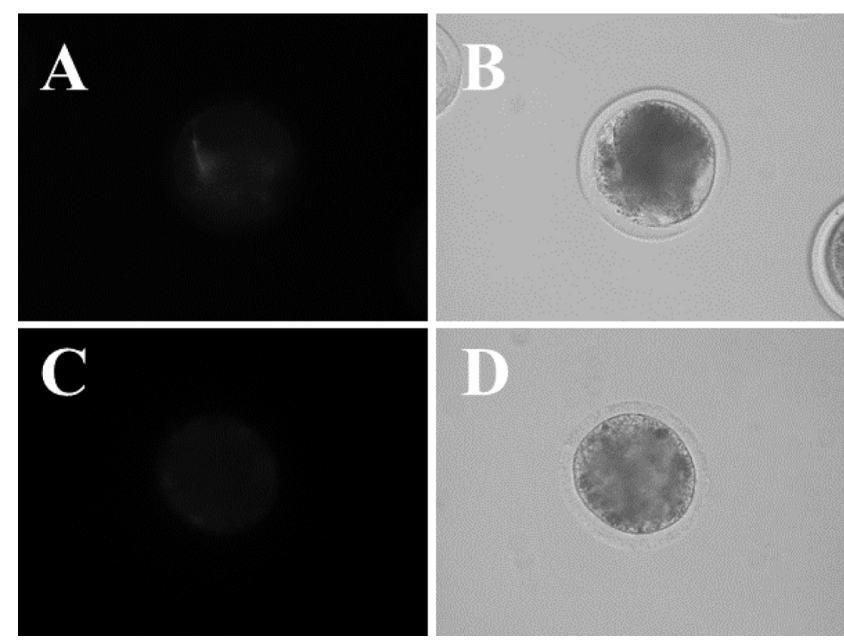

Fig. 2. Representative images of oocytes stained with MitoTracker Orange CMTM Ros A, C; Images of oocytes from HL cows (A) and DL cows (C) stained with MitoTracker Orange CMTM Ros. B, C; Images of oocytes collected from HL cows (B) and DL cows (D).

Table 3. Effect of liver conditions on cortical granule distribution before and after IVF

\begin{tabular}{|c|c|c|c|c|c|c|c|c|}
\hline \multirow{2}{*}{ Liver conditions } & \multirow{2}{*}{$\begin{array}{l}\text { No. of } \\
\text { trials }\end{array}$} & \multirow{2}{*}{$\begin{array}{l}\text { No. of } \\
\text { oocytes }\end{array}$} & \multicolumn{3}{|c|}{ Before IVF $(\%$, Mean \pm SE $)$} & \multirow{2}{*}{$\begin{array}{c}\text { No. of } \\
\text { trials }\end{array}$} & \multirow{2}{*}{$\begin{array}{c}\text { No. of } \\
\text { oocytes }\end{array}$} & \multirow{2}{*}{$\frac{\text { After IVF }(\%, \text { Mean } \pm \text { SE })}{\text { Released }}$} \\
\hline & & & Complete & Incomplete & Immature & & & \\
\hline HL & 4 & 82 & $65.7 \pm 1.5^{\mathrm{a}}$ & $19.7 \pm 5.0^{\mathrm{a}}$ & $14.6 \pm 4.8$ & 4 & 33 & $65.7 \pm 4.9^{\mathrm{a}}$ \\
\hline DL & 4 & 93 & $22.6 \pm 4.8^{b}$ & $51.7 \pm 3.8^{b}$ & $25.7 \pm 0.6$ & 4 & 36 & $33.3 \pm 4.8^{b}$ \\
\hline
\end{tabular}

Values with different letters differ significantly $(\mathrm{a}-\mathrm{b} ; \mathrm{P}<0.05)$.

Table 4. Effect of liver conditions on mtDNA number in oocytes

\begin{tabular}{ccccc}
\hline \multirow{2}{*}{ Liver conditions } & \multirow{2}{*}{$\begin{array}{c}\text { No. of } \\
\text { cows }\end{array}$} & \multirow{2}{*}{$\begin{array}{c}\text { No. of } \\
\text { oocytes }\end{array}$} & \multicolumn{2}{c}{ mtDNA number (Mean \pm SE) } \\
\cline { 4 - 5 } & 20 & 400 & $239,962.35 \pm 17,310.43$ & After IVM culture \\
\hline HL & 20 & 400 & $229,493.51 \pm 10,848.78$ & $329,238.49 \pm 10,109.82$ \\
DL & 20 & &
\end{tabular}

Table 5. Effect of liver conditions on mitocondrial membrane potential of oocytes

\begin{tabular}{ccccc}
\hline \multirow{2}{*}{$\begin{array}{c}\text { Liver } \\
\text { conditions }\end{array}$} & $\begin{array}{c}\text { No. of } \\
\text { trials }\end{array}$ & $\begin{array}{c}\text { No. of } \\
\text { oocytes }\end{array}$ & \multicolumn{2}{c}{$\begin{array}{c}\text { Mitocondrial memblane potential } \\
\text { (Fluorescence intensity, Mean } \pm \text { SE) }\end{array}$} \\
\cline { 4 - 5 } & & & GV & After IVM culture \\
\hline HL & 4 & 80 & $130.99 \pm 2.88$ & $180.67 \pm 4.68^{\text {a }}$ \\
DL & 4 & 80 & $127.57 \pm 3.11$ & $122.58 \pm 5.07^{\mathrm{b}}$ \\
\hline
\end{tabular}

Values with different letters differ significantly $(\mathrm{a}-\mathrm{b} ; \mathrm{P}<0.05)$.

DL cows (Fig. 2 and Table 5, $\mathrm{P}<0.05$ ).

\section{Experiment 6}

The ATP content of GV stage oocytes was similar between the two liver conditions, whereas the ATP content in oocytes derived
Table 6. Effect of liver conditions on ATP content in oocytes

\begin{tabular}{|c|c|c|c|c|}
\hline \multirow{2}{*}{$\begin{array}{c}\text { Liver } \\
\text { conditions }\end{array}$} & \multirow{2}{*}{$\begin{array}{c}\text { No. of } \\
\text { cows }\end{array}$} & \multirow{2}{*}{$\begin{array}{c}\text { No. of } \\
\text { oocytes }\end{array}$} & \multicolumn{2}{|c|}{$\operatorname{ATP}(\mathrm{pM}, \mathrm{Mean} \pm \mathrm{SE})$} \\
\hline & & & GV & After IVM culture \\
\hline $\mathrm{HL}$ & 30 & 300 & $2.25 \pm 0.12$ & $3.08 \pm 0.28^{\mathrm{a}}$ \\
\hline DL & 50 & 500 & $1.91 \pm 0.17$ & $1.94 \pm 0.18^{b}$ \\
\hline
\end{tabular}

Values with different letters differ significantly $(a-b ; P<0.05)$.

from HL cows was higher than that from DL cows after maturation culture (HL vs. DL, 3.08 vs. 1.94 pM, Table 6). 


\section{Discussion}

In this study, we found that oocytes collected from donor cows with liver damage had low fertilization abilities and low-functioning mitochondria. CGs are derived from the Golgi complex [26]; at the GV stage, CGs are distributed throughout oocytes, forming clusters. The distribution of CGs changes during nuclear maturation, during which time CGs localize under the oocyte membrane [27, 28]. Exocytosis of the CGs triggered by sperm entry-associated calcium release from the endoplasmic reticulum changes the characteristics of the ZP [27], an important system that prevents polyspermic fertilization [28]. The present study showed that oocytes collected from the ovaries of DL cows had poor CG distribution in post-IVM oocytes and incomplete release of CGs as well as low ZP hardening following IVF treatment. These results indicate that the abnormal distribution and poor exocytosis resulted in a high frequency of abnormal fertilization.

Nearly all ATP is generated in the mitochondria in oocytes [29], and ATP content in oocytes is higher during the MII stage than the GV stage, indicating that high ATP content is a prerequisite for successful oocyte maturation $[10,18,30]$. In the present study, we compared mitochondrial function by measuring ATP content and membrane potential between the two liver conditions. The values were found to be similar between the two liver conditions in GV stage oocytes, but at the end of the maturation periods, oocytes derived from DL cows showed lower ATP content and mitochondrial membrane potential compared with oocytes derived from HL cows. Energy consumption was enhanced after GV breakdown [31], suggesting that defects in the mitochondria of oocytes derived from DL cows emerge during the period when active mitochondrial respiration is required. $\mathrm{CG}$ distribution is a marker of oocyte cytoplasmic maturation, and the distribution pattern is reportedly regulated by microfilaments whose polymerization depends on ATP [28, 32, 33]; this suggests that low ATP content during oocyte maturation prevents proper CG migration. In addition, we previously showed that the timing of GV breakdown was delayed in oocytes derived from DL cows, whereas the final maturation rates were similar in oocytes from HL and DL cows $[7,8]$. Thus, the short duration of nuclear maturation may limit the proper distribution of CGs.

Reynier et al. [34] reported that oocytes with poor fertilization ability contained low numbers of mitochondria. Wai et al. [15] reported that a minimum threshold (50000 copy) is required for fertilization and that the number of mitochondria does not affect the fertilization outcome. In the present study, the mtDNA copy numbers between the two liver conditions were similar in both the GV and after maturation cultures. Mitochondria that are closely associated with the endoplasmic reticulum play a role in calcium release and uptake, and high ATP levels are required for proper calcium oscillation $[11,35]$. Furthermore, high mitochondrial membrane potential is closely related to proper CG release [36]. Based on previous studies and the present results, low ATP and fluorescent intensity of the MitoTracker dye in oocytes of DL cows was not attributed to the low mitochondrial quantity but to the low quality of mitochondria. The low mitochondrial functions of oocytes from DL cows likely reduced the fertilization outcome.

In the present study, causal factors for mitochondrial dysfunction in oocytes derived from DL cows remain unclear. The liver is an important organ with versatile functions, including energy homeostasis and providing endocrinal factors. In our previous study, we characterized the differences between serum and follicular fluid (FF) under two liver conditions. The concentrations of several factors including lactate dehydrogenase, calcium, inorganic phosphorus, and albumin in the serum differ between the two liver conditions $[8,9]$. Additionally, the characteristics of FF are closely related to that of the serum, and the FF of DL cows contained significantly lower concentrations of growth factors and albumin and higher total protein than that of HL cows [9]. We reported that the addition of FF collected from DL cows to IVM medium reduced oocyte development [9], but the fertilization outcome was comparatively high. The present study and our previous study [8] showed that culturing oocytes in IVM medium containing FCS increased the rate of abnormal fertilization of oocytes derived from DL cows compared with those from HL cows. Furthermore, oocytes collected from HL cows were divided into two groups and cultured in medium containing $10 \%$ of FF collected from HL or DL cows (Supplementary Table 1: online only). Mitochondrial functions in post-IVM oocytes determined by measuring mitochondrial membrane potentials and ATP content were similar between the two follicular origins. This suggests that some beneficial factors contained in the FF may mask the adverse effects of liver damage on the fertilization ability of oocytes, or defects stemming from liver damage had already accumulated in oocytes and granulosa cells before the onset of nuclear maturation. In agreement with this finding, we previously reported that oocytes collected from early antral follicles of DL cows showed low developmental ability compared with those from HL cows [8].

However, further studies are needed to clarify the molecular background underlying liver damage associated with mitochondrial dysfunction and abnormal fertilization.

In conclusion, oocytes derived from cows with liver damage contained low numbers of functional mitochondria, increasing the abnormal fertilization of oocytes because of the incomplete distribution and release of CGs.

\section{Acknowledgments}

This work was supported by JSPS KAKENHI (Grant Numbers $26 \bullet 8274$ and 25450400$)$.

\section{References}

1. Walsh SW, Williams EJ, Evans AC. A review of the causes of poor fertility in high milk producing dairy cows. Anim Reprod Sci 2011; 123: 127-138. [Medline] [CrossRef]

2. Leroy JL, Opsomer G, Van Soom A, Goovaerts IG, Bols PE. Reduced fertility in high-yielding dairy cows: are the oocyte and embryo in danger? Part I. The importance of negative energy balance and altered corpus luteum function to the reduction of oocyte and embryo quality in high-yielding dairy cows. Reprod Domest Anim 2008; 43: 612-622. [Medline] [CrossRef]

3. Leroy JL, Van Soom A, Opsomer G, Goovaerts IG, Bols PE. Reduced fertility in highyielding dairy cows: are the oocyte and embryo in danger? Part II. Mechanisms linking nutrition and reduced oocyte and embryo quality in high-yielding dairy cows. Reprod Domest Anim 2008; 43: 623-632. [Medline] [CrossRef]

4. McCarthy SD, Waters SM, Kenny DA, Diskin MG, Fitzpatrick R, Patton J, Wathes DC, Morris DG. Negative energy balance and hepatic gene expression patterns in high-yielding dairy cows during the early postpartum period: a global approach. Physiol Genomics 2010; 42A: 188-199. [Medline] [CrossRef] 
5. Wathes DC, Fenwick M, Cheng Z, Bourne N, Llewellyn S, Morris DG, Kenny D, Murphy J, Fitzpatrick R. Influence of negative energy balance on cyclicity and fertility in the high producing dairy cow. Theriogenology 2007; 68(Suppl 1): S232-S241. [Medline] [CrossRef]

6. Leroy JL, Rizos D, Sturmey R, Bossaert P, Gutierrez-Adan A, Van Hoeck V, Valckx S, Bols PE. Intrafollicular conditions as a major link between maternal metabolism and oocyte quality: a focus on dairy cow fertility. Reprod Fertil Dev 2011; 24: 1-12. [Medline] [CrossRef]

7. Tanaka H, Takeo S, Monji Y, Kuwayama T, Iwata H. Maternal liver damage delays meiotic resumption in bovine oocytes through impairment of signalling cascades originated from low p38MAPK activity in cumulus cells. Reprod Domest Anim 2014; 49: 101-108. [Medline] [CrossRef]

8. Iwata H, Tanaka H, Kanke T, Sakaguchi Y, Shibano K, Kuwayama T, Monji Y. Follicle growth and oocyte developmental competence in cows with liver damage. Reprod Domest Anim 2010; 45: 888-895. [Medline]

9. Tanaka H, Shibano K, Monji Y, Kuwayama T, Iwata H. Liver condition affects bovine oocyte qualities by changing the characteristics of follicular fluid and plasma. Reprod Domest Anim 2013; 48: 619-626. [Medline] [CrossRef]

10. Sarentonglaga B, Ogata K, Taguchi Y, Kato Y, Nagao Y. The developmental potential of oocytes is impaired in cattle with liver abnormalities. J Reprod Dev 2013; 59: 168-173. [Medline] [CrossRef]

11. Dumollard R, Duchen M, Sardet C. Calcium signals and mitochondria at fertilisation. Semin Cell Dev Biol 2006; 17: 314-323. [Medline] [CrossRef]

12. Stojkovic M, Machado SA, Stojkovic P, Zakhartchenko V, Hutzler P, Gonçalves PB, Wolf E. Mitochondrial distribution and adenosine triphosphate content of bovine oocytes before and after in vitro maturation: correlation with morphological criteria and developmental capacity after in vitro fertilization and culture. Biol Reprod 2001; 64: 904-909. [Medline] [CrossRef]

13. Dumollard R, Marangos P, Fitzharris G, Swann K, Duchen M, Carroll J. Spermtriggered $[\mathrm{Ca} 2+]$ oscillations and $\mathrm{Ca} 2+$ homeostasis in the mouse egg have an absolute requirement for mitochondrial ATP production. Development 2004; 131: 3057-3067. [Medline] [CrossRef]

14. Tamassia M, Nuttinck F, May-Panloup P, Reynier P, Heyman Y, Charpigny G, Stojkovic M, Hiendleder S, Renard JP, Chastant-Maillard S. In vitro embryo production efficiency in cattle and its association with oocyte adenosine triphosphate content, quantity of mitochondrial DNA, and mitochondrial DNA haplogroup. Biol Reprod 2004; 71: 697-704. [Medline] [CrossRef]

15. Wai T, Ao A, Zhang X, Cyr D, Dufort D, Shoubridge EA. The role of mitochondrial DNA copy number in mammalian fertility. Biol Reprod 2010; 83: 52-62. [Medline] [CrossRef]

16. Ge H, Tollner TL, Hu Z, Dai M, Li X, Guan H, Shan D, Zhang X, Lv J, Huang C, Dong $\mathbf{Q}$. The importance of mitochondrial metabolic activity and mitochondrial DNA replication during oocyte maturation in vitro on oocyte quality and subsequent embryo developmental competence. Mol Reprod Dev 2012; 79: 392-401. [Medline] [CrossRef]

17. Takahashi Y, First NL. In vitro development of bovine one-cell embryos: Influence of glucose, lactate, pyruvate, amino acids and vitamins. Theriogenology 1992; 37: 963-978. [Medline] [CrossRef]

18. Iwata H, Goto H, Tanaka H, Sakaguchi Y, Kimura K, Kuwayama T, Monji Y. Effect of maternal age on mitochondrial DNA copy number, ATP content and IVF outcome of bovine oocytes. Reprod Fertil Dev 2011; 23: 424-432. [Medline] [CrossRef]

19. Yamamoto T, Iwata H, Goto H, Shiratuki S, Tanaka H, Monji Y, Kuwayama T. Effect of maternal age on the developmental competence and progression of nuclear maturation in bovine oocytes. Mol Reprod Dev 2010; 77: 595-604. [Medline] [CrossRef]
20. Takeo S, Goto H, Kuwayama T, Monji Y, Iwata H. Effect of maternal age on the ratio of cleavage and mitochondrial DNA copy number in early developmental stage bovine embryos. J Reprod Dev 2013; 59: 174-179. [Medline] [CrossRef]

21. Takeo S, Sato D, Kimura K, Monji Y, Kuwayama T, Kawahara-Miki R, Iwata H. Resveratrol improves the mitochondrial function and fertilization outcome of bovine oocytes. J Reprod Dev 2014; 60: 92-99. [Medline] [CrossRef]

22. Coy P, Gadea J, Romar R, Matás C, García E. Effect of in vitro fertilization medium on the acrosome reaction, cortical reaction, zona pellucida hardening and in vitro development in pigs. Reproduction 2002; 124: 279-288. [Medline] [CrossRef]

23. Modina S, Beretta M, Lodde V, Lauria A, Luciano AM. Cytoplasmic changes and developmental competence of bovine oocytes cryopreserved without cumulus cells. Eur J Histochem 2004; 48: 337-346. [Medline]

24. Torner H, Brüssow KP, Alm H, Ratky J, Pöhland R, Tuchscherer A, Kanitz W. Mitochondrial aggregation patterns and activity in porcine oocytes and apoptosis in surrounding cumulus cells depends on the stage of pre-ovulatory maturation. Theriogenology 2004; 61: 1675-1689. [Medline] [CrossRef]

25. Kuzmina TI, Alm H, Denisenko V, Tuchscherer A, Kanitz W, Torner H. Effect of recombinant bovine somatotropin (rbST) on cytoplasmic maturation of bovine oocytes and their developmental competence in vitro. J Reprod Dev 2007; 53: 309-316. [Medline] [CrossRef]

26. Wessel GM, Brooks JM, Green E, Haley S, Voronina E, Wong J, Zaydfudim V, Conner S. The biology of cortical granules. Int Rev Cytol 2001; 209: 117-206. [Medline] [CrossRef]

27. Thibault C, Szöllösi D, Gérard M. Mammalian oocyte maturation. Reprod Nutr Dev 1987; 27: 865-896. [Medline] [CrossRef]

28. Hosoe M, Shioya Y. Distribution of cortical granules in bovine oocytes classified by cumulus complex. Zygote 1997; 5: 371-376. [Medline] [CrossRef]

29. Itami N, Shiratsuki S, Shirasuna K, Kuwayama T, Iwata H. Mitochondrial biogenesi and degradation are induced by CCCP treatment of porcine oocytes. Reproduction 2015; 150: 97-104. [Medline] [CrossRef]

30. Brevini TA, Vassena R, Francisci C, Gandolfi F. Role of adenosine triphosphate, active mitochondria, and microtubules in the acquisition of developmental competence of parthenogenetically activated pig oocytes. Biol Reprod 2005; 72: 1218-1223. [Medline] [CrossRef]

31. Dalton CM, Szabadkai G, Carroll J. Measurement of ATP in single oocytes: impact of maturation and cumulus cells on levels and consumption. J Cell Physiol 2014; 229 353-361. [Medline] [CrossRef]

32. Nagano M, Takahashi Y, Katagiri S. In vitro fertilization and cortical granule distribution of bovine oocytes having heterogeneous ooplasm with dark clusters. $J$ Vet Med Sci 1999; 61: 531-535. [Medline] [CrossRef]

33. Sun QY, Lai L, Park KW, Kühholzer B, Prather RS, Schatten H. Dynamic events are differently mediated by microfilaments, microtubules, and mitogen-activated protein kinase during porcine oocyte maturation and fertilization in vitro. Biol Reprod 2001; 64: 879-889. [Medline] [CrossRef]

34. Reynier P, May-Panloup P, Chrétien MF, Morgan CJ, Jean M, Savagner F, Barrière P, Malthièry Y. Mitochondrial DNA content affects the fertilizability of human oocytes. Mol Hum Reprod 2001; 7: 425-429. [Medline] [CrossRef]

35. Calì T, Ottolini D, Negro A, Brini M. Enhanced parkin levels favor ER-mitochondri crosstalk and guarantee $\mathrm{Ca}(2+)$ transfer to sustain cell bioenergetics. Biochim Biophys Acta 2013; 1832: 495-508. [Medline] [CrossRef]

36. Van Blerkom J, Davis P. Mitochondrial signaling and fertilization. Mol Hum Reprod 2007; 13: 759-770. [Medline] [CrossRef] 